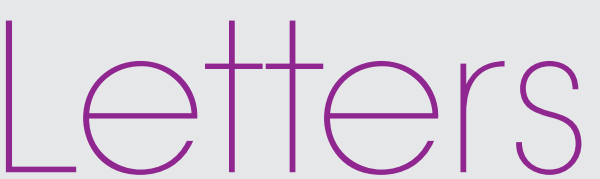

Email bdjteam@nature.com

Or comment on Facebook www.facebook.com/boljteam

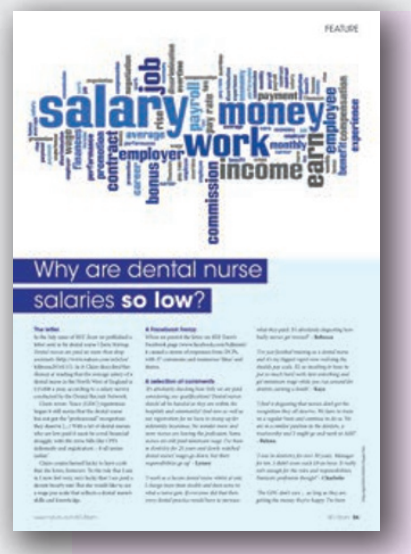

\title{
The profession does not acknowledge the progress dental nurses have made
}

Dear Editor, I read your article in the October issue of $B D J$ Team on dental nurse salaries with interest (Why are dental nurse

salaries so low? http://www.nature.com/ articles/bdjteam2016152).

Low pay is always a topic of conversation with dental nurses and it has been enhanced by registration due to having to pay for their courses and indemnity as well. Some lucky dental nurses have forward thinking employers who embrace team working and lifelong learning but in my experience most do not.

As you know prior to registration a dental nurse's salary did not need to be amazing because they held fewer responsibilities. When I was in practice in the $80 \mathrm{~s}$ and $90 \mathrm{~s}$, before registration, and looking back, I felt I was viewed as the 'lady with the sucker' and the 'hand holder' by the profession and patients. Dental nurses did not need a qualification and perhaps for this reason they did not gain the due recognition by the profession or patients. Despite my dental nurse training at King's College Hospital in the 80 s, when I entered general practice my salary was less than the receptionist's!

This is a bit of a sweeping statement, but perhaps the mindset of the profession has not changed from the pre-registration days and this is still why salaries are low? Plus I feel that our current economic climate (times of austerity) is perhaps feeding reasons to save money.

Dentistry is unlike medicine, in that registered nurses are subject to a national pay scale, whereas registered dental nurses are not. The profession does not acknowledge the progress dental nurses have made over the last eight years. When I have a classroom of registered dental nurses studying on one of our courses, I know that the dental nurse students will be on different salaries with different terms and conditions. Most of them will have to forfeit nurses. The new NHS prevention contract is supposed to influence the use of DCPs but that is not here yet. General nurses raised the profile of their status through the degree

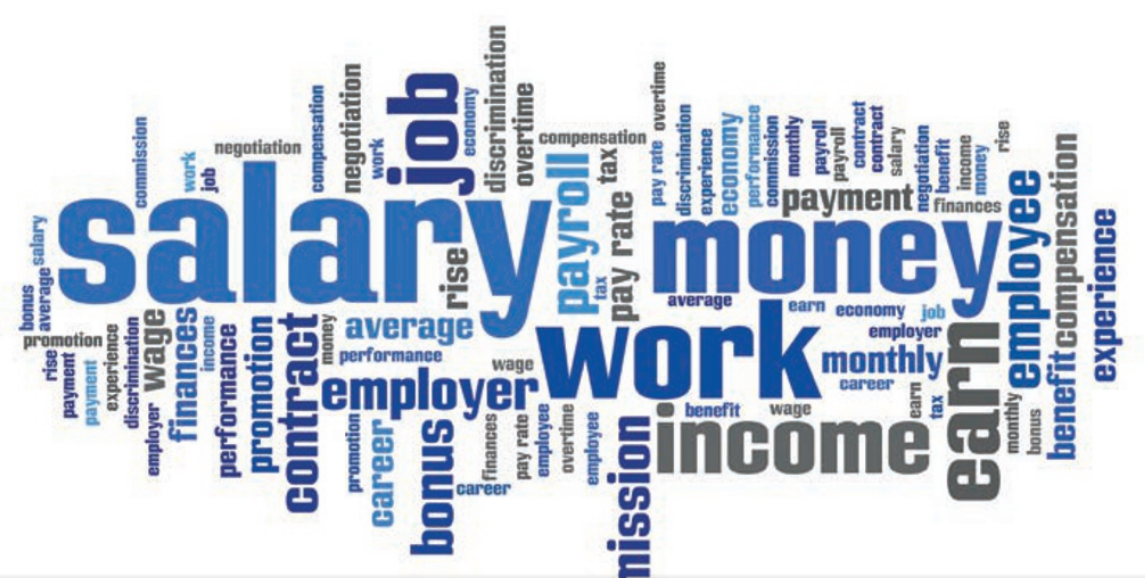

'WHEN I WAS IN PRACTICE IN THE 8OS AND 90s,

BEFORE REGISTRATION, I FELT I WAS VIEWED AS

THE “LADY WITH THE SUCKER" AND THE “HAND

HOLDER" BY THE PROFESSION AND PATIENTS.'

a day's pay to attend the study days or take annual leave, and in addition the majority of the students will have had to pay for the course themselves. The cost of maintaining their registration is also a topic of discussion. The cost of day CPD courses, the cost of indemnity, and travel to courses is not reimbursed. CPD is normally undertaken in their own time for reasons that I mentioned before (most DNs are not paid when they are not in practice).

One way, in my opinion, is for dental nurses to work together, with one voice, through their professional association to raise their profile and to have conversations with relevant bodies to discuss a nationally funded framework for training/national salary scales for dental programme; perhaps dental nurses should be doing the same?

Jacqui Elsden, Dental Education Facilitator, London and the South East, Health Education England working across Kent, Surrey and Sussex 